\title{
Chronic total occlusion successfully treated with a bioresorbable everolimus-eluting vascular scaffold
}

\author{
Juan Carlos Rama-Merchan, Alessio Mattesini, Gianni Dall'Ara, Carlo Di Mario \\ Cardiovascular Biomedical Research Unit, Royal Brompton Hospital and Harefield Trust, London, United Kingdom
}

Postep Kardiol Inter 2014; 10, 2 (36): 128-129 DOI: $10.5114 /$ pwki.2014.43521

Abstract

Fully bioresorbable vascular scaffolds (BVS) are a new approach to the percutaneous treatment of coronary artery disease. The BVS have not yet been fully tested in complex lesions, including chronic total occlusion (CTO). We report a CTO case successfully treated with a second-generation bioabsorbable drug-eluting scaffold.

Key words: chronic total occlusion, bioresorbable vascular scaffold.

Fully bioresorbable vascular scaffolds (BVS) are a new approach to the percutaneous treatment of coronary artery disease. These scaffolds provide transient vessel support and drug delivery to the vessel wall without the potential long-term limitations of a traditional metallic drug-eluting stent (DES). The BVS have been shown to res-
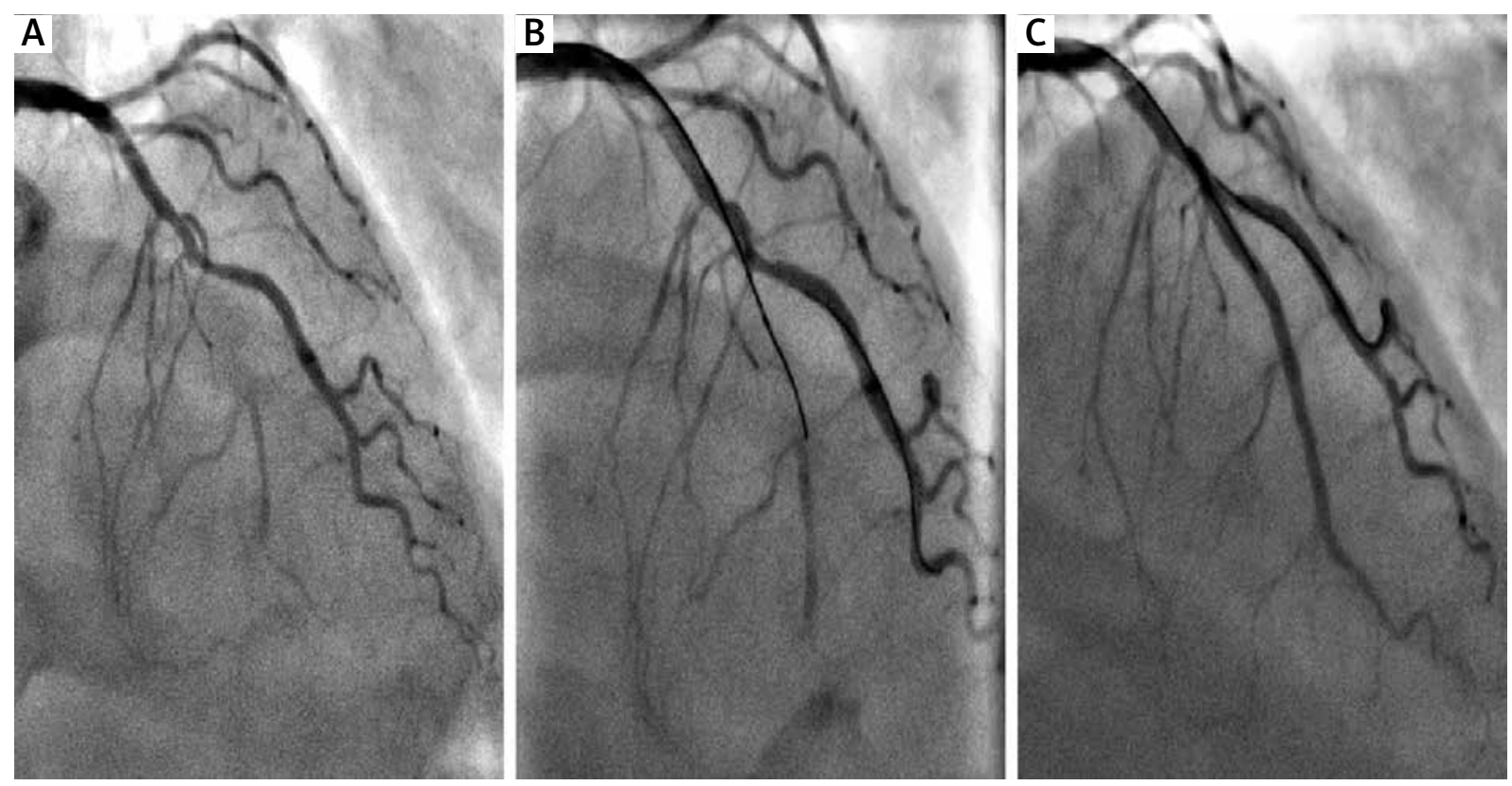

Figure 1. Coronary angiography. A - Basal coronary angiography revealed total occlusion of the mid-portion of the LAD coronary artery. The distal vessel of this artery was visualized by homocoronary collateral circulation. B - Coronary angiography during LAD CTO recanalization by antegrade approach. The lesion was crossed with a Confianza-Pro ${ }^{\circledR} 12$ (Asahi Intecc) wire advanced through a Finecross ${ }^{\circledR}$ (Terumo) catheter. C - Coronary angiography after Absorb BVS ${ }^{\circledR} 2.5 \mathrm{~mm} \times 28 \mathrm{~mm}$ deployment in the mid-segment of the LAD. Final angiogram showed satisfactory results with TIMI 3 flow

\section{Corresponding author:}

Juan Carlos Rama-Merchan MD, Cardiovascular Biomedical Research Unit, Royal Brompton Hospital and Harefield Trust, 0012 London, United Kingdom, phone: +34923291100, e-mail: ramamerchan@hotmail.com

Received: 1.04.2014, accepted: 8.05.2014. 

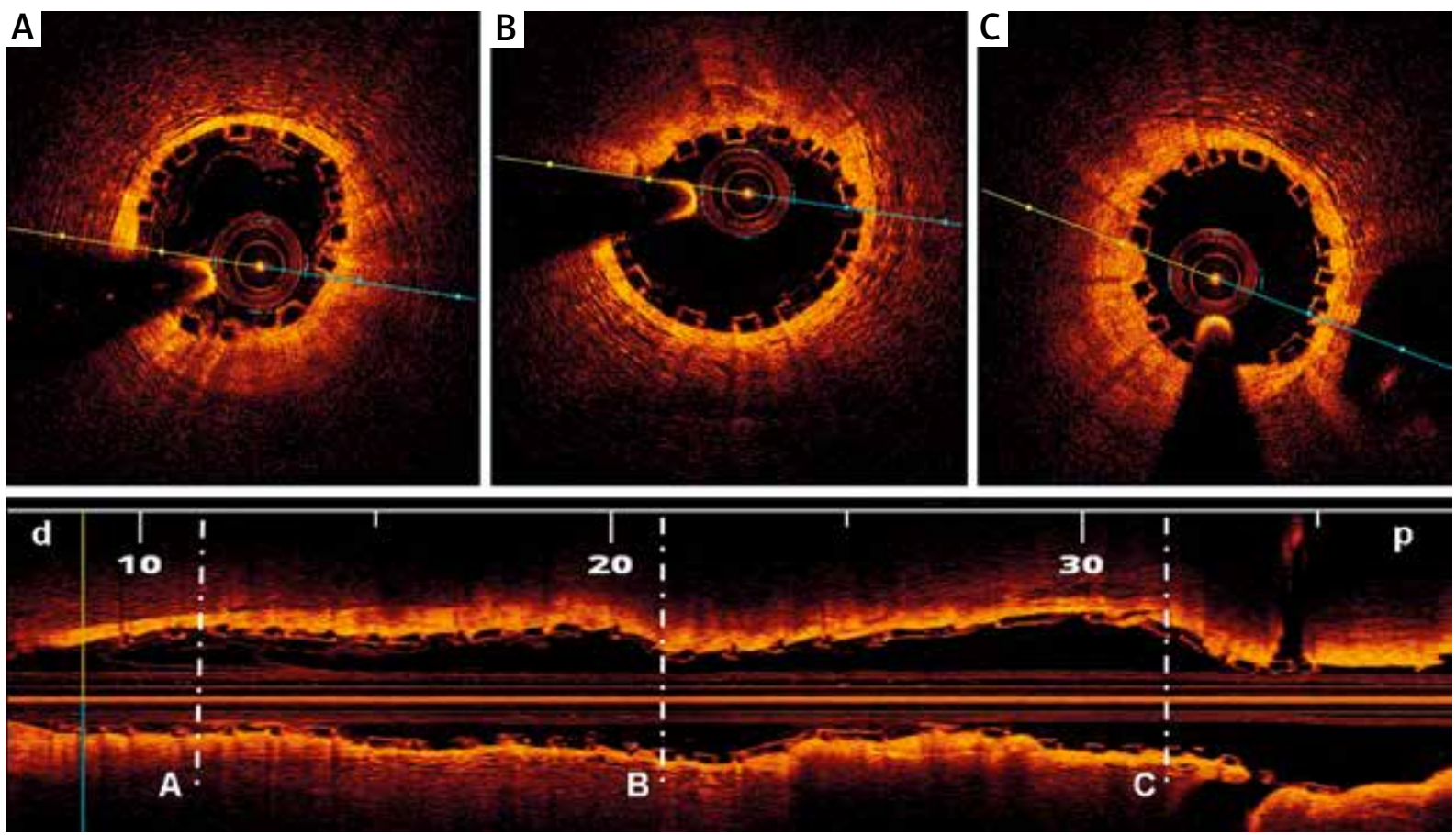

Figure 2. Optical coherence tomography-derived cross-sectional image demonstrated complete stent strut apposition post-intervention. OCT images of the distal (A), middle (B), and proximal (C) segment of the scaffold are shown

$d$-distal, $p$-proximal

tore vascular function and enable positive vascular remodelling; they also do not preclude coronary artery bypass grafting [1-3]. However, BVS have not yet been fully tested in complex lesions, including chronic total occlusion (CTO).

We report a CTO case successfully treated with a second-generation bioabsorbable drug-eluting scaffold.

A 52-year-old woman with type 1 diabetes was admitted to our centre due to severe chronic stable angina. A myocardial perfusion test revealed significant ischaemia involving the anterior wall. The patient underwent coronary angiography which demonstrated total occlusion of the mid-portion of the left anterior descending (LAD) coronary artery (Figure $1 \mathrm{~A}$ ). Percutaneous coronary intervention $(\mathrm{PCl})$ was performed using a conventional antegrade approach and an everolimus $2.5 \mathrm{~mm} \times 28 \mathrm{~mm}$ BVS 1.1 (Absorb BVS, Abbott Vascular, Santa Clara, CA, USA) was implanted in the LAD (Figure $1 \mathrm{~B}$ ). The scaffold was post-dilated with a $2.5-\mathrm{mm}$ non-compliant balloon, slowly inflated at 12 ATM.

The final angiogram showed satisfactory results with TIMI 3 flow in the LAD (Figure $1 \mathrm{C}$ ). Frequency domain optical coherence tomography (FD-OCT) pullback was performed on the implanted scaffold (C7 System, St Jude Medical, St Paul, USA). Longitudinal view and cross-sections demonstrated good strut apposition and scaffold expansion (Figure 2). At the 6-month follow-up the patient remained asymptomatic.

\section{References}

1. Ormiston JA, Serruys PW, Regar E. A bioabsorbable everolimus-eluting coronary stent system for patients with single de-novo coronary artery lesions (ABSORB): a prospective open-label trial. Lancet 2008; 371: 899-907.

2. Serruys PW, Garcia-Garcia HM, Onuma Y. From metallic cages to transient bioresorbable scaffolds: change in paradigm of coronary revascularization in the upcoming decade? Eur Heart J 2012; 33: $16-25$.

3. Onuma Y, Serruys PW. Bioresorbable scaffold: the advent of a new era in percutaneous coronary and peripheral revascularization? Circulation 2011; 123: 779-97. 